\title{
The coast and benefits of helicopter emergency medical services instead of the ground unit in traumatic patients: A cost-effectiveness analysis
}

\author{
Amin Shams Akhtari ${ }^{1 *}$, Naghmeh Sadat Jafari ${ }^{2}$, Hamid Kariman ${ }^{1}$, Afshin Amini ${ }^{1}$, \\ Vahid Monsef ${ }^{3}$, Mohamad Noorizadeh ${ }^{4}$, Neda Gholizadeh ${ }^{5}$ \\ ${ }^{1}$ Department of Emergency Medicine, Shahid Beheshti University of Medical Science, Tehran, Iran; \\ *Corresponding Author: Amin.may1981@gmail.com \\ ${ }^{2}$ Department of Forensic Medicine and Traumatic Pathology, Alborz University of Medical Science, Karaj, Iran \\ ${ }^{3}$ Research Committee of Medical Science, Jondishapour University of Medical Science, Ahvaz, Iran \\ ${ }^{4}$ Department of Emergency Medicine, Gilan University of Medical Science, Rasht, Iran \\ ${ }^{5}$ Department of Radiation Medical Engineering, Isfahan University, Isfahan, Iran
}

Received 1 March 2013; revised 15 April 2013; accepted 1 May 2013

Copyright (C 2013 Amin Shams Akhtari et al. This is an open access article distributed under the Creative Commons Attribution License, which permits unrestricted use, distribution, and reproduction in any medium, provided the original work is properly cited.

\section{ABSTRACT}

Study objective: Aero medical crews offer an advanced level of practice and rapid transport to definitive care; however, their efficacy remains unproven. Previous studies have used relatively small sample sizes or have been unable to adequately control the effect of other potentially influential variables. Here we explore the impact of aero medical response in patients with moderate to severe traumatic brain injury. Methods: This was a cross-sectional study using our county trauma registry. All patients with trauma injury, who referred to our emergency department by helicopter or car, were included. The impact of aeromedical response was determined using logistic regression, adjusting for age, sex, mechanism, preadmission Glasgow Coma Scale score and Injury Severity Score. Finally, the aeromedical patients undergoing field intubation were compared with ground patients undergoing emergency department (ED) intubation. Results: A total of 243 patients meeting all inclusion and exclusion criteria and with complete data sets were identified. Overall mortality was $25 \%$ in the air- and ground-transported cohorts, but outcomes were not significantly better for the aeromedical patients when adjusted for age, sex, mechanism of injury, hypotension, Glasgow Coma Scale score, head Abbreviated Injury Score, and Injury Severity Score (adjusted odds ratio [OR] $1.90 ; 95 \%$ confidence interval $[\mathrm{Cl}] 1.60$ to 2.25 ; P:
0001). Good outcomes (discharge to home, jail, psychiatric facility, rehabilitation, or leaving against medical advice) were also higher in aeromedical patients (adjusted OR 1.36; 95\% Cl 1.18 to 1.58; P: 0001). Conclusion: Here we analyze a large database of patients with moderate to severe traumatic brain injury. Aeromedical response appears to yield no significantly improved outcomes after adjustment for multiple influential factors in patients with moderate to severe traumatic brain injury.

Keywords: Emergency; Traumatic Patients; Aero Medical

\section{BACKGROUND}

Trauma is one of the common causes of death which has a considerable loss of productivity and subsequent social and economic damage [1-3]. This factor is the fourth most frequent cause of death in the UK and the first reason of the loss of life in the young people in Iran.

In spite of this high level importance of trauma care, many studies have reported that almost of the patients received less than good standard care practice with prehospital care and trauma networks [4]. The importance of emergency medical services in the care of traumatic patients has increased with the development of out-hospital emergency care and transport [5,6].

In Iran, patients usually are transported by the ground ambulance and rarely by the helicopter emergency medical service (HEMS). 
The HEMS, which is the most rapid and expensive way of patients' transfer, was started during the Korean War as a part of emergency health services and now a day are widely used in Europe and the US. The first time of using helicopter transfer for trauma patients in Iran was about 1981 during Iran-Iraq war. Now there are more than 25 helicopter air ambulances in Iran.

The utilization of helicopters in the transport of trauma patients is thought to confer some benefits such as the patients transportation from remote areas or Facilitation of rapid transport of a specialist team to the scene of injury (systematic review) [7-9]. Therefore, many of health system staffs believe that air-medical transport is critical in regionalized health care systems for acutely injured patients $[3,7]$.

Although little is known about the risk of adverse clinical outcomes associated with air transport, patients may deteriorate in transit because of progression of underlying diseases, the physical stress of transport, or care delivered before or during transportation [10]. For now, there is no general agreement and solid evidence of the benefit of this practice and it remains as a considerable debate whether helicopter deployment for trauma patients is cost effective [11-15].

This is partly due to conflicting reports in the research literature on the impact of HEMS on trauma mortality, lower incidence of major trauma and the high cost of airframes and support [16-18].

HEMS in different areas and different setting could have completely different effects and health benefits due to geography, population density, traffic conditions and emergency medical service (EMS) design.

In this study, we evaluated the services of a paramedical HEMS operating in the Emergency department. It seems that early and fast transport of trauma patients is life saving. There is no consensus on the superiority of the HMT cost-effective in comparison with the GMT. The aim of our study was to investigate the potential health benefits of HEMS and their relation to the cost of this service.

\subsection{Methods \& Materials}

The helicopter is located in the town of Tehran, and it is manned by a pilot and two paramedics licensed who can provide full ALS care. The service area of HEMS is $400 \mathrm{KM}$ within $30 \mathrm{~min}$ of flying time on average. The helicopter operated $24 \mathrm{~h}$ /day throughout the year. The conditions of ground units are the same with a driver and two paramedics' licensed which operate 24 h/day throughout the year but usually use for urban area and closer distances.

As a cross-sectional study, we screened all traumatic patients treated by the HEMS or ground ambulances who referred to Imam Khomeini Hospital between April 2011 and September of 2012. We obtained data on the clinical and demographic characteristics of patients. The data included the place of accident, distance from hospital, and pre-hospital GCS and vital signs and other complications.Statistical analysis was performed by the SPSS software version 16 .

We retrospectively scored their Injury Severity based on Injury Severity Score (ISS) and followed them through seven days to estimate the final condition.

To calculate predicted Mortality based on injury severity and physical sign, we used TRISS formula by entering the data to its special site estimated mean mortality of them by this formula and take the difference between the mean of predicted mortality and real mortality in traumatic patients [8].

As a next step, to estimate the cost of different emergency medical services by recourse to the health ministry, we took the annual running cost of HEMS and Ground ambulance.

The Regional Ethics Committee of Tehran University of Medical Sciences (TUMS) approved the collection and recording of the study data.

\subsection{Statistics}

We generated descriptive statistics with secondary analyses stratified according to sex, injury, type of sending site and geography. We assessed variables for co linearity and used multivariable logistic regression to identify factors that were independently associated with in-transit critical events. We used the Kruskal-Wallis test for medians and chi-square test for binary and categorical variables for comparisons across groups.

\section{RESULT}

We identified 243 transports of traumatic patients by HEMS or ground ambulances during the study period, 135 (55.6\%) patients by HEMS and 108 (44.4\%) by ground unit. Characteristics of patients and transports in two groups are shown in Table 1. Patient characteristics are varied but not significantly different in the two groups. Further, the significantly patient origin is more rural areas in HEMS and more urban in Ground unit ( $\mathrm{p}<$ $0.05)$.

To compare the final outcomes and cost in two groups, we divided different clinical conditions in 4 categories: death on-scene, at the time of arrival, under surgery and discharge from hospital. The result showed that the HEMS had significantly more death on-scene (31.1\%) and surgical patients (40\%) in contrast of ground units (p value: 0.007$)$ detail showed in Table 2.

In addition, General Consciousness Score GCS is significantly different in the two groups. We had 13 patients with severely decreased level of consciousness (GCS 3 $8), 5$ patients were moderate but decreased level of con- 
Table 1. The characteristics of patients in HEMS and ground unit transportation.

\begin{tabular}{cccc}
\hline Variables & HEMS & Ground unit & P-value \\
\hline Mean age & 31.47 & 29.61 & N.S \\
Sex (male) & 105 & 84 & N.S \\
Sex (female) & 30 & 24 & N.S \\
Home & 0 & 15 & Sig. \\
Work place & 18 & 12 & Sig. \\
Rural area & 90 & 24 & Sig. \\
Urban area & 27 & 57 & Sig. \\
\hline
\end{tabular}

Table 2. The frequency and percentage of death in the HEMS and ground unit transportation.

\begin{tabular}{cccc}
\hline & $\begin{array}{c}\text { Clinical } \\
\text { condition }\end{array}$ & Frequency & Percentage \\
\hline $\begin{array}{c}\text { On-scene } \\
\text { Death in the } \\
\text { ground units } \\
\text { transportation }\end{array}$ & $\begin{array}{c}\text { At the time of } \\
\text { arrival } \\
\text { Under surgery } \\
\text { After } \\
\text { discharge }\end{array}$ & 11 & $25.7 \%$ \\
$\begin{array}{c}\text { Death in the } \\
\text { HEMS }\end{array}$ & $\begin{array}{c}\text { At the time of } \\
\text { arrival }\end{array}$ & 23 & $2.8 \%$ \\
transportation & $\begin{array}{c}\text { Under surgery } \\
\text { After }\end{array}$ & 18 & $63.9 \%$ \\
\hline & discharge & 13 & $41.1 \%$ \\
\hline
\end{tabular}

sciousness (GCS 9 - 13) and 31 mild cases in HEMS group. But in Ground unit transport we did not have any severe decreased level of consciousness and only 15 cases and 63 in moderate or mild level.

More, the costs of transport medical patients in each of the separate groups were evaluated by resource of the health ministry or hospital information. There is a significant difference between the cost of pre-hospital care in different type of medical care transfer (P value: 0.045 ). So $35.6 \%$ of patients in group transferred by air spending more than $500 \$$ but only $11.1 \%$ which transferred by ground (Table 3).

As a next step, we calculated ISS and RTS of each patient in two groups separately and examined the difference with paired T-test. The result indicated that there is a significant difference among ISS and RTS in two groups of patients transferred. The ISS mean in HEMS transferred was about 12.93 and 6.66 in ground units. It was also applied to the RTS mean in HEMS and ground units (6.73 and 7.69).
Table 3. The cost of transportation in HEMS and ground unit.

\begin{tabular}{cccc}
\hline & $\begin{array}{c}\text { Cost of } \\
\text { transportation }\end{array}$ & Frequency & Percentage \\
\hline HEMS & $0 \$-200 \$$ & 24 & $17.8 \%$ \\
transportation & $200 \$-500 \$$ & 63 & $46.7 \%$ \\
& $>500 \$$ & 48 & $35.6 \%$ \\
Ground unit & $0 \$-200 \$$ & 27 & $25 \%$ \\
transportation & $200 \$-500 \$$ & 69 & $63 \%$ \\
& $>500 \$$ & 12 & $11.1 \%$ \\
\hline
\end{tabular}

Finally, to obtain independent effect of each variable on the patients' outcome logistic regression analysis were used. All variables in this study like as the type of transmission, RTS, GCS, cost, ISS, TRIS, age, gender included in the multi factorial model for its own specific effect on patients outcome. By removing confounding effects of different variables on each other with SPSS, we estimated the specific effect of all variables on outcome.

The final model consisted that RTS and GCS were determined only independent factors effect on the probability of death. Contrary to initial bi-variant analysis different type of transmission could not have an effect on mortality rate by its own and it will affect because of different primary ISS and RTS level of patients in two different transferred types.

The above results showed that for every unit increase in RTS the incidence of death will increase five times (CI $95 \%$ equals $8.44 \pm 1.1$ ). And per unit increase in level of consciousness incidence of death decrease 0.537 times (CI 95\% equals $3.11 \pm 0.9$ ). It was also the same relationship between the level of consciousness and death in the first 24 hours was observed. So for every unit increase in level of consciousness probability of death will decrease 1.92 times.

\section{DISCUSSION}

Helicopter transport is an expensive and limited resource, and to our knowledge the question of cost effectiveness of air medical transfer on the mortality of trauma patients has not been addressed previously [11, $16,17,19]$.

The logistical and ethical barriers to a randomized controlled trial comparing HEMS with GMT in the transport of trauma patients are numerous. This has resulted just in some cohort or cross-sectional studies forming our present knowledge. The strategies used to assess trauma care are also limited and are ably discussed by Thomas et al. [20].

In recognition of these limitations of the current evidence base, careful consideration must be given to the 
cost-effectiveness of running active HEMS [1,21-23].

Most of the studies supporting the use of helicopters in prehospital care have beneficial effects in patients with trauma $[7,24,25]$. In the US air-transported trauma patients had 52\% lower mortality than that of patients transported by ground [5]. In London, only the most seriously injured trauma patients benefited from HEMS [12].

In a different setting, HEMS could cause different outcomes. In some of them it appears economically viable and in some of them not $[17,26]$. Gearhart et al. showed helicopter transport was cost-effective in truma patients [27], Moreover the variables under which helicopter transport of patients with acute myocardial infarction for primary angioplasty [12]. And Silbergleit et al. indicates helicopter transfer of patients with suspected acute ischemic stroke for potential thrombolysis is cost-effective for a wide range of system variables [13,28].

On the other hands, some studies indicated that, different factors could affect on HEMS efficacy [11,29,30]. The study of 792 trauma patients showed that HEMS are associated with higher levels of pre-hospital medical care and faster transportation than ground EMS .However the $\mathrm{Z}$ test for independent populations demonstrated no significant difference in mortality between two groups [14].

Also in study by Nardi et al. which patients of HEMS had better outcomes, there was no significant difference in the pre hospital times. They mentioned the improved survival in HEMS group may be due to the technical interventions performed [31,32].

All these reports indicated that different case complication and service configuration may have contributed to difference effectively. As a summary, reviews show that HEMS is an effective transmitter way for pre medical care with a good safety record but it needs strict criteria to select appropriate patients to be cost-effective [33].

In addition most of the HEMS missions were about the rural area with crash accident and higher level of injury and it may not be justified to compare the benefit of HEMS in rural areas to the potential benefit in densely populated urban areas [29,34-36]. We estimated that overall only a minority of patients who received HEMS are benefited from.

On the other hand, by our data collection in 2010 the cost per mission (a mission in which a patient was attended) could cost between $200 \$$ and $500 \$$ depending on service configuration on the other hand every ground unit will cost around $100 \$$.

HEMS in the Iran are currently operated by government and funded by public health budget and insurance and it was a serious conflict to decide about the cost effectiveness of this expensive emergency services.

\section{CONCLUSION}

The HEMS procedures are a part of the chain of sur- vival but applied alone, it is seldom life saving. The beneficial effects of having helicopter emergency services are about rural areas and out of reach origin. In general, the benefit is mainly due to HEMS procedures on-scene and the cost per beneficial mission is high. It could be more cost-effective if we used HEMS selectively just for special mission and cases. All the aspects should be considered to improve management of patients in different situation and further evaluation of these aspects seems to be necessary.

\section{REFERENCES}

[1] Warren, J., Fromm Jr., R.E., Orr, R.A., Rotello, L.C. and Horst, H.M. (2004) Guidelines for the inter- and intrahospital transport of critically illpatients. Critical Care Medicine, 32, 256-262.

[2] Alexander, R.H., Pons, P.T., Kriscuer, J. and Hunt, P. (1984) The effect of advance life support and sophisticated hospital on motor vehicles mortality. The Journal of Trauma, 24, 486-490. doi:10.1097/00005373-198406000-00005

[3] Celli, P., Fruin, A. and Cervoni, L. (1997) Severe head trauma: Review of the factors influencing the prognosis. Minerva Chirurgica, 52, 1467-1480.

[4] Boyd, D., Mains, K. and Flashner, B. (1973) A systems approach to statewide emergency medical care. The Journal of Trauma, 13, 267-284. doi:10.1097/00005373-197304000-00002

[5] Thomas, F., Clemmer, T.P. and Orme, J.F. (1985) A survey of advance truma life support procedure being performance by physicians and nurses on hospital aeromedical evacuation services. Aviation, Space, and Environmental Medicine, 56, 1213-1215.

[6] Finch, H.F., Nareff, M.J. and Watkins, P.B. (1967) Wings for wounded warriors. JAMA, 200, 391-398. doi:10.1001/jama.1967.03120180079012

[7] McVey, J., Petrie, D.A. and Tallon, J.M. (2010) Air versus ground transport of the major trauma patient: A natural experiment. Prehospital Emergency Care, 14, 45-50.

[8] Shatney, C.H., Homan, S.J., Sherck, J.P., et al. (2002) The utility of helicopter transport of trauma patients from the injury scene in an urban trauma system. The Journal of Trauma, 53, 817-822. doi:10.1097/00005373-200211000-00002

[9] Talving, P., Teixeira, P.G.R., Barmparas, G., DuBose, J., Inaba, K., et al. (2009) Helicopter evacuation of trauma victims in Los Angeles: Does it improve survival? World Journal of Surgery, 33, 2469-2476. doi:10.1007/s00268-009-0185-1

[10] Cunningham, P., Rutledge, R., Baker, C.C., et al. (1997) A comparison of the association of helicopter and ground ambulance transport with the outcome of injury in trauma patients transported from the scene. Journal of Trauma, 43, 940-946. doi:10.1097/00005373-199712000-00013

[11] Evans, C., Howes, D., Pickett, W. and Dagnone, L. (2009) Audit filters for improving processes of care and clinical 
outcomes in trauma systems. Cochrane Database of Systematic Reviews, Article ID: CD007590.

[12] Olson, C.M., Jastremski, M.S., Vilogi, J.P., Madden, C.M. and Beney, K.M. (1987) Stabilization of patients prior to interhospital transport. American Journal of Emergency Medicine, 5, 33-39. doi:10.1016/0735-6757(87)90285-3

[13] Ehrenworth, J., Sorbo, S. and Hackel, A. (1986) Transport of critically ill adults. Critical Care Medicine, 14, 543547. doi:10.1097/00003246-198606000-00005

[14] Kanter, R. and Tompkins, J. (1989) Adverse events during interhospital transport: Physiologic deterioration associated with pretransport severity of illness. Pediatrics, 84, 43-48.

[15] Borlase, B.C., Baxter, J.K., Kennedy, P.R., Forse, R.A., Benotti, P.N. and Blackburn, G.L. (1991) Elective intrahospital admissions versus acute interhospital transfers to a surgical intensive care unit: Cost and outcome prediction. Journal of Trauma, 31, 915-918. doi:10.1097/00005373-199107000-00006

[16] Mackenzie, P.A., Smith, E.A. and Wallace, P.G.M. (1997) Transfer of adults between intensive care units in the UK. British Medical Journal, 314, 1455-1456. doi:10.1136/bmj.314.7092.1455

[17] Emily, A., Bosk, M.S.W., Veinot, T. and Iwashyna, T.J. (2011) Which patients, and where: A qualitative study of patient transfers from community hospitals. Medical Care, 49, 592-598. doi:10.1097/MLR.0b013e31820fb71b

[18] Chappell, V.L., Mileski, W.J., Wolf, S.E., et al. (2002) Impact of discontinuing a hospital-based air ambulance service on trauma patient outcomes. Journal of Trauma, 52, 486-491. doi:10.1097/00005373-200203000-00012

[19] Gore, J.M. (1989) Feasibility and safety of emergency interhospital transport of patients during the early hours of acute myocardial infarction. Archives of Internal Medicine, 149, 353-355. doi:10.1001/archinte.1989.00390020075015

[20] Thomas, S.H., Harrison, T.H., Buras, W.R., et al. (2002) Helicopter transport and blunt trauma mortality: A multicenter trial. Journal of Trauma, 52, 136-145. doi:10.1097/00005373-200201000-00023

[21] Harrahil, M. and Bartkus, E. (1990) Preparing the trauma patient for transfer. Journal of Emergency Nursing, 16, 25-28.

[22] Lambert, S.M. and Willett, K. (1993) Transfer of multiply-injured patients for neurosurgical opinion: A study of the adequacy of assessment and resuscitation. Injury, 24, 333-336. doi:10.1016/0020-1383(93)90058-E

[23] Henderson, A., Coyne, T., Wall, D. and Miller, B. (1992) A survey on interhospital transfer of head-injured patients with inadequately treated life-threatening extracranial injuries. Australian and New Zealand Journal of Surgery, 62, 759-762. doi:10.1111/j.1445-2197.1992.tb06913.x

[24] Jacobs, L.M., Gabram, S.G., Sztajnkrycer, M.D., et al. (1999) Helicopter air medical transport: Ten-year outcomes for trauma patients in a New England program. Connecticut Medicine, 63, 677-682.
[25] Garner, A., Rashford, S., Lee, A., et al. (1999) Addition of physicians to paramedic helicopter services decreases blunt trauma mortality. Australian and New Zealand Journal of Surgery, 69, 697-701. doi:10.1046/j.1440-1622.1999.01688.x

[26] Dragsted, L., Jorgensen, J., Jensen, N.H., Bonsing, E., Jacobsen, E., Knaus, W.A. and Qvist. J. (1989) Interhospital comparisons of patient outcomes from intensive care: Importance of lead-time bias. Critical Care Medicine, 17, 418-422. doi:10.1097/00003246-198905000-00008

[27] Gearhart, P., Wuerz, R. and Localio, A. (1997) Cost-effectiveness analysis ofhelicopter EMS for trauma patients. Annals of Emergency Medicine, 30, 500-506. doi:10.1016/S0196-0644(97)70010-6

[28] Silbergleit, R., Scott, P.A., Lowell, M.J. and Silbergleit, R. (2003) Cost-effectiveness of helicopter transport of stroke patients for thrombolysis. Academic Emergency Medicine, 10, 966-972.

[29] Fan, E., MacDonald, R.D., Adhikari, N.K.J., Scales, D.C., et al. (2006) Outcomes of interfacility critical care adult patient transport: A systematic review. Critical Care, 10, R6. doi:10.1186/cc3924

[30] Durairaj, L., Will, J.G., Torner, J.C. and Doebbeling, B.N. (2003) Prognostic factors for mortality following interhospital transfers to the medical intensive care unit of a tertiary referral center. Critical Care Medicine, 31, 19811986. doi:10.1097/01.CCM.0000069730.02769.16

[31] Nardi, G., Massarutti, D., Muzzi, R., et al. (1994) Impact of emergency medical helicopter service on mortality for trauma in North-East Italy: A regional prospective audit. European Journal of Emergency Medicine, 1, 69. doi:10.1097/00063110-199406000-00004

[32] Martin, G., Cogbill, T., Landercasper, J. and Strutt, P.J. (1990) Prospective analysis of rural interhospital transfer of injured patients to a referral trauma center. Journal of Trauma, 30, 1014-1020. doi:10.1097/00005373-199008000-00011

[33] Valenzuela, T., Criss, E., Copass, M., Luna, G.K. and Rice, C.L. (1990) Critical care air transportation of the severely injured: Does long distance transport adversely affect survival? Annals of Emergency Medicine, 19, 169-172. doi:10.1016/S0196-0644(05)81803-7

[34] Grieve, C.F., Ferguson, N.D., Adhikari, N., Singh, J.M., Moneta, S.L., DeMajo, W., Stewart, T.E. and Scales, D.C. (2005) Utilization pattern of Ontario's critical care referral and transfer facilitation program [abstract]. Proceedings of the American Thoracic Society, 2, A597.

[35] Kerr, H.D. and Byrd, J.C. (1989) Community hospital transfers to a VA Medical Center. Journal of the American Medical Association, 262, 70-73. doi:10.1001/jama.1989.03430010082035

[36] Durairaj, L., Will, J.G., Torner, J.C. and Doebbeling, B.N. (2003) Prognostic factors for mortality following interhospital transfers to the medical intensive care unit of a tertiary referral center. 31, 1981-1986. 